\title{
Understanding organic potato fertilization dynamics at Intermountain REC
}

S

trong consumer demand and high prices are

encouraging an increasing number of potato growers

to consider organic production. Growing organic

potatoes introduces new complexities for nutrient and pest

management - complexities that Intermountain Research

and Extension Center (IREC) Director Rob Wilson and Daniel

Geisseler, a UC ANR Cooperative Extension specialist based

at UC Davis, are unraveling in an ongoing experiment.

Researchers at

IREC are evaluating

different organic

amendment

and cover crop

treatments for

organic potato

production.
IREC, in the Siskiyou County town of Tulelake, serves the Klamath Basin farming region, an area of roughly 200,000 acres of irrigated land on the California-Oregon border that is one of the leading potato-growing regions for both states. At an elevation of roughly 4,000 feet and with a high desert climate, farming conditions in the basin are quite different from the Central Valley and other low-elevation agricultural regions of California.

Potatoes have a relatively high demand for nitrogen, and organic growers have two general ways to provide it: organic amendments like manure, compost and blood meal; or nitrogen-fixing cover crops, such as varieties of vetch or field peas.

Wilson and Geisseler are teasing out the costs and benefits of the various options and developing nutrient-monitoring plans to guide growers' management decisions. While the work is tailored to the needs of potato growers in the Klamath Basin, it will also help to expand the understanding of nutrient dynamics in organic farming systems more broadly.

In organic farming systems, meeting a crop's nitrogen need is complicated because the available sources, whether cover crops or amendments, provide nitrogen in a form - organic nitrogen - that is not directly available to plants. By contrast, the fertilizers used on conventional farms generally provide nitrogen in plant-available forms - ammonia and nitrate known as mineral forms of nitrogen.

Soil microbes convert organic nitrogen to ammonia and then to nitrate. Mineralization takes time, and it happens at a different rate depending on the source - the nitrogen in chicken manure is mineralized more quickly than that in steer manure, for instance. The rate is also influenced by environmental variables such as soil type and temperature. The mineralization timetable is important because potatoes need a significant amount of nitrogen in the early stages of their life cycle, before the potato tubers start to grow in earnest.

One objective of the research project is to evaluate how the nitrogen mineralization process proceeds for cover crop residues. Around $90 \%$ of the nitrogen in a nitrogen-fixing cover crop is contained in the aboveground plant tissue. To convert that nitrogen into a

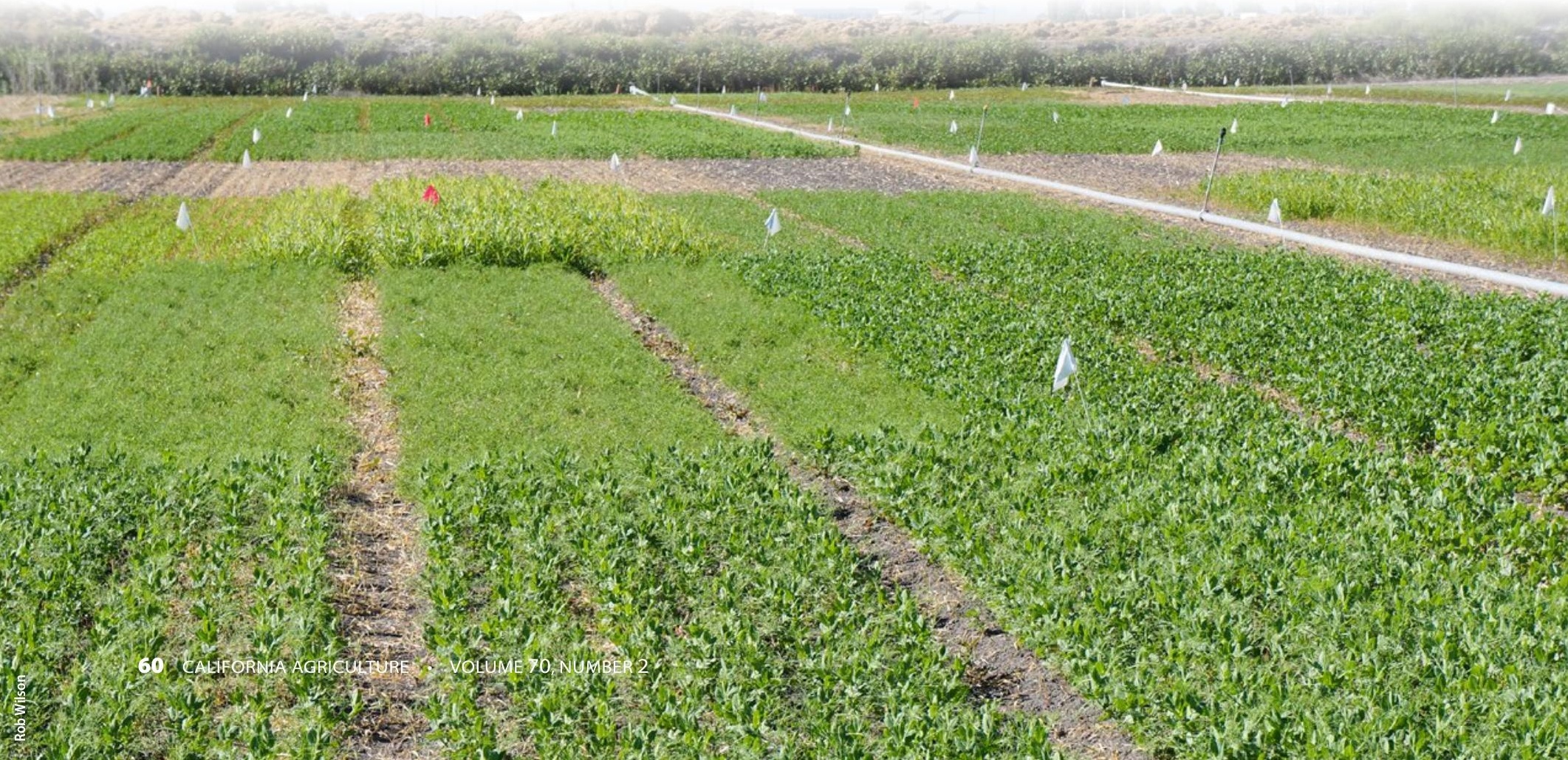


useful fertilizer, the crop must be chopped and tilled into the soil, where soil microbes can mineralize it.

"By determining how much nitrogen is mineralized, we can help growers have a better understanding of the value of the amendments and the different cover crops," said Wilson.

Cost is another comparison point. Per pound of nitrogen provided to the crop, the direct costs of growing a cover crop are generally lower than the cost of organic amendments - and there doesn't appear to be a yield penalty. In the first year of tests, potato yields from fields

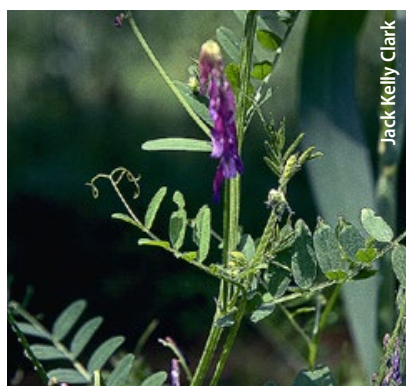

Woollypod vetch (Vicia villosa ssp. dasycarpa). "fertilized" by cover crops - woolypod vetch and hairy vetch - were greater than those from comparison plots treated with organic amendments or with urea, a conventional nitrogen fertilizer.

The cost comparison is complicated, however, by considerations such as the availability of irrigation water to crop the year before planting potatoes may displace a cash crop. To better assess the range of costs associated with growing a cover crop, Wilson and Geisseler will try growing several varieties at different times of the year and with and without irrigation. grow a cover crop, and the fact that growing a cover

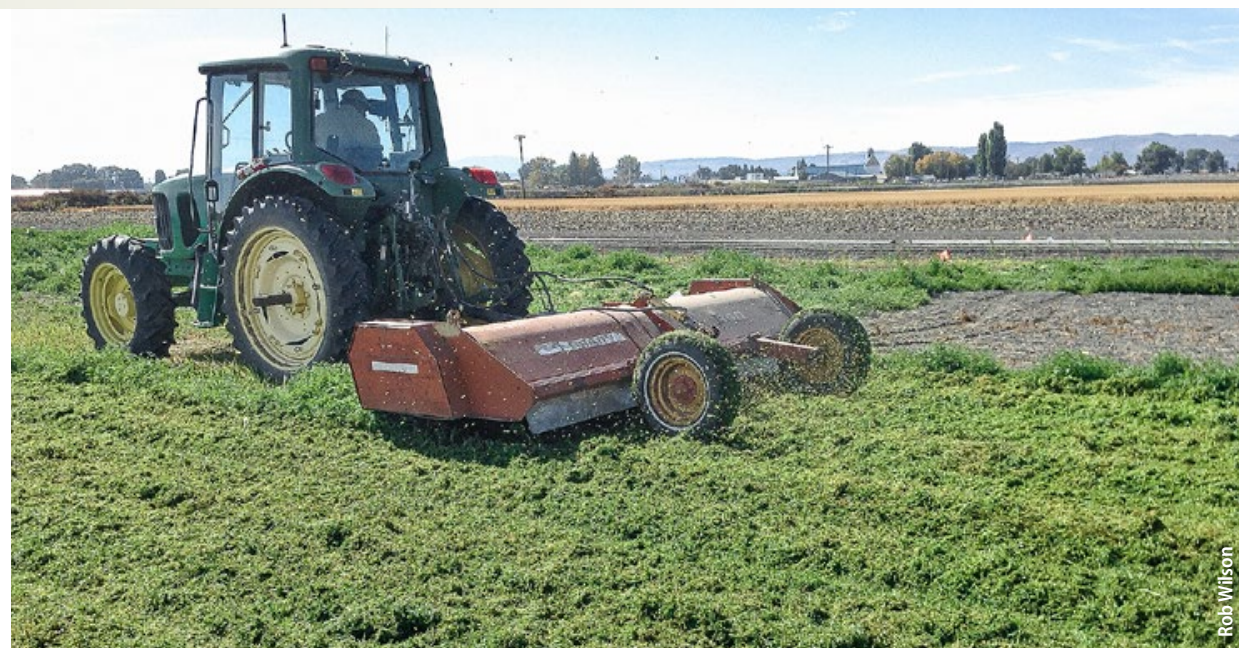

To make the organic nitrogen in the cover crop available to the next crop planted in the field, the cover crop is chopped, above, and then tilled into the soil, where the nitrogen is mineralized by microbes.

In the coming year, Wilson and Geisseler will be evaluating 11 different organic amendment treatments and 17 cover crop treatments, experimenting with adding amendments and planting cover crops to find the best treatments for Tulelake potato production.

A future direction for the work will be to evaluate the pest management benefits and pitfalls of cover crops in an organic potato system. Mustard cover crops, for instance, can act as biofumigants, though they do not provide a nitrogen benefit. Some legumes, on the other hand, have been shown to increase certain fungal diseases and nematodes. Wilson said it may be possible to grow a combination of crops - a blend of mustard and a nitrogen-fixing legume, for instance - to get the benefits of both. CA

$$
\text { — Jim Downing }
$$
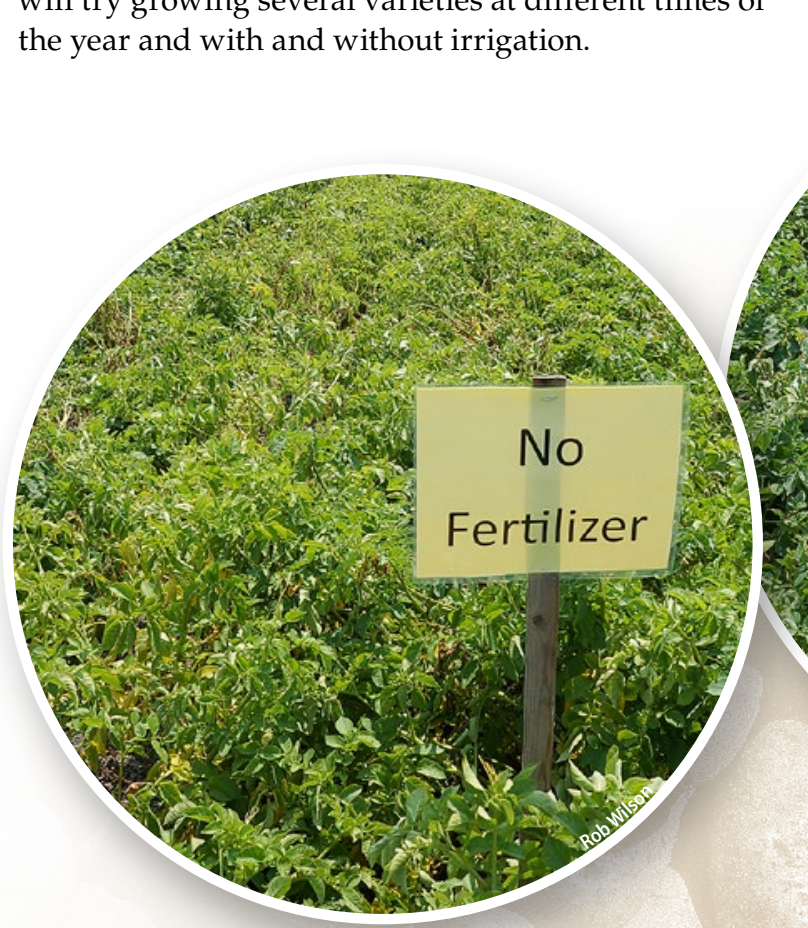